TẠP CHÍ KHOA HỌC ĐẠI HỌC TÂN TRÀO
ISSN: $2354-1431$

\title{
QUẢN LÍ XUNG ĐỘT, NÂNG CAO HÒA KHÍ VÀ PHÁT TRIỂN VĂN HÓA NHÀ TRƯỜnG ĐẠI HỌC
}

\author{
Đặng Thành Hung ${ }^{l}$, Trần Thị Tố Oanh ${ }^{2}$ \\ ${ }^{1}$ Truòng Đại học Su phạm Hà Nội 2 \\ ${ }^{2}$ Viện Khoa học giáo dục Việt Nam \\ Email:nga970@gmail.com
}

\section{Thông tin bài viết}

Ngày nhận bài:

25/07/2020

Ngày duyệt đăng:

20/9/2020

\section{Tóm tắt}

Văn hóa ứng xử học đường là một bộ phận của văn hóa nhà trường. Nó liên quan đến quản lí xung đột, làm dịu và nâng cao hòa khí trong tổ chức cho nên đòi hỏi phải tiếp cận những vấn đề này theo phong cách tham gia. Bài này góp phần lí giải một số trong những vấn đề đó.

Tù khóa:

Văn hóa ưng xủ, văn hóa nhà truò̀ng, quản lý xung đột, phát triển văn hóa trong truòng đại hoc

\section{Đặt vấn đề}

Văn hóa ứng xử học đường (VHUX) là một trong những lĩnh vực của văn hóa nhà trường, tức là văn hóa tổ chức tại một cơ sở giáo dục. Những vấn đề chủ yếu của VHUXX hiện đại có liên quan trực tiếp đến quản lí xung đột, duy trì và nâng cao hòa khí trong nhà trường. Và chúng cần được xem xét từ tiếp cận văn hóa tổ chức trong đó tất cả những thành viên trong hệ thống đều tham gia phát triển văn hóa nhà trường với những vai trò cụ thể.

\section{Nội dung nghiên cứu}

1. Văn hóa ứng xử -một thành tố của văn hóa nhà trường

\subsection{Bản chất của văn hóa nhà trường}

Văn hóa nhà trường nói chung hợp thành từ 4 loại giá trị:

1. Những giá trị trung tâm gắn kết mọi thành viên nhà trường lại với nhau, cả trường đều tôn trọng và hành động, ứng xử theo yêu cầu của chúng, là những gì mà mọi người muốn học, muốn sở hữu, muốn chia sẻ với nhau và khát khao làm được đúng như thế.

2. Những giá trị truyền thống nổi bật được mọi thành viên hiểu biết và tôn thờ, có tính nguyên tắc, luôn được mọi người vun đắp, giữ gìn và trân trọng, có vai trò khích lệ, đoàn kết và thu hút mọi người chung suy nghĩ, hành động và ứng xử mỗi khi nảy sinh vấn đề trong tổ chức, có tác động như những tấm gương từ thế hệ trước để lại cho thế hệ sau.

3. Những giá trị có tính chất tiêu biểu và khác biệt của riêng, làm nên nét độc đáo của nhà trường, không có ở tổ chức khác ngay cả khi đó là những tổ chức cùng loại, gọi đơn giản là bản sắc, có thể là đạo đức, năng lực, văn hóa hay mẫu hành vi chung, và làm cho nhà trường trở nên khác biệt.

4. Những liên hệ và ràng buộc hữu cơ giữa các giá trị và truyền thống, là thứ giá trị cấp cao nhất, kết dính tất cả những giá trị và truyền thống kể trên, trở 
thành linh hồn của trường, chi phối phong cách, lề lối làm việc và giao dịch, năng lực và văn hóa, đạo đức của mọi người trong công việc và ứng xử, làm cho trường có tính toàn vẹn, bền vững và thuần khiết [5].

Tất cả những giá trị trên có loại công khai, có loại ngầm định [3], [12], [14]. Công khai như tuyên bố sứ mạng, tầm nhìn, triết lí cơ bản của tổ chức, khẩu hiệu, logo, phong cách trang phục, mẫu hành vi, nghi thức giao dịch, ngôn ngữ làm việc và giao tiếp của nhân viên, thương hiệu và những thành tựu tiêu biểu công khai, các cuộc vận động như tổ chức sự kiện, họp báo, quảng cáo, truyền thông, thi đua, cách thức tham gia đời sống xã hội, phương pháp làm ăn v.v... Ngầm định như tư duy, định hướng giá trị cốt lõi, niềm tin bên trong v.v...

\subsection{Cấu trúc của văn hóa nhà truò̀ng}

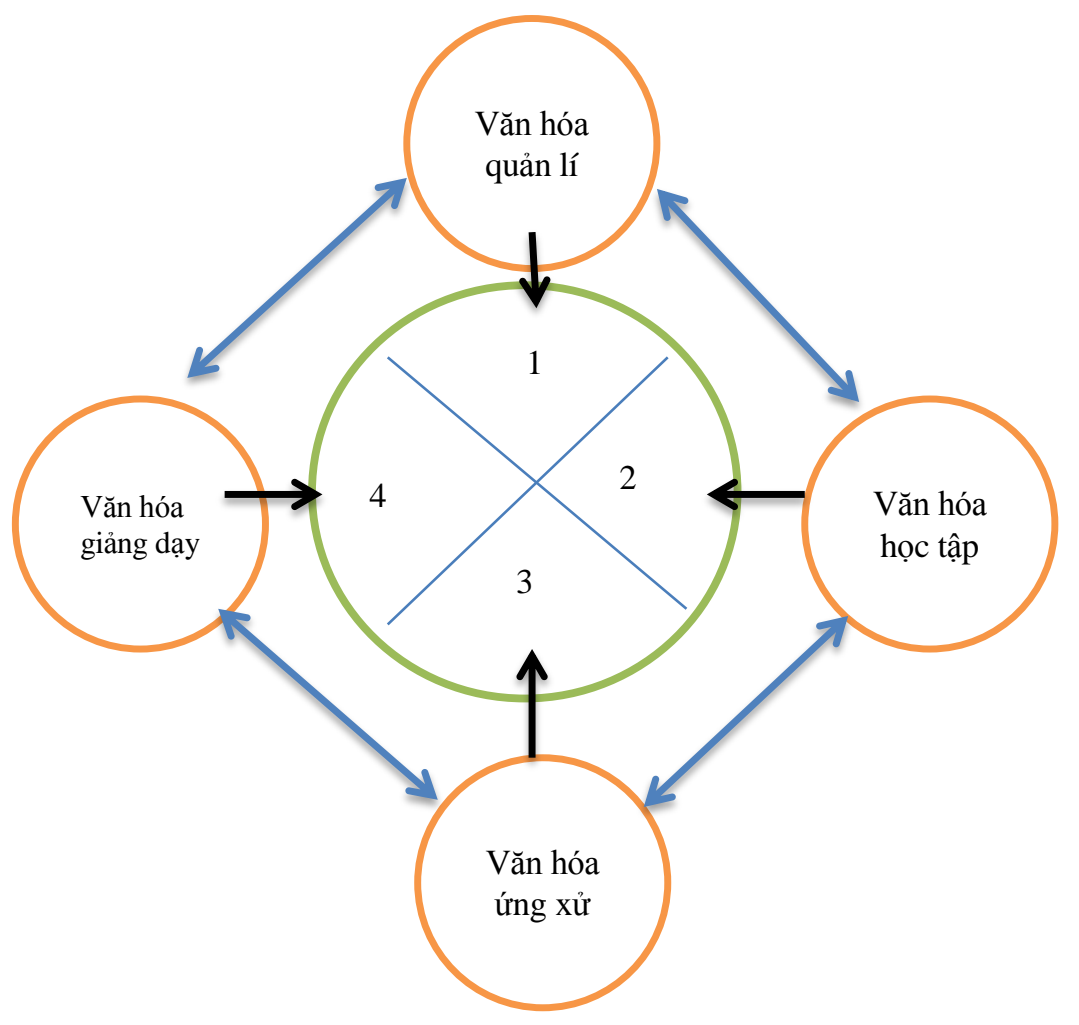

Có nhiều cách tiếp cận nội hàm văn hóa nhà trường nên cũng xuất hiện nhiều khái niệm khác nhau, tùy theo mỗi người nhấn mạnh khía cạnh khác nhau. Ở đây hiểu văn hóa nhà truờng là văn hóa tổ chức gắn liền với sú mạng và hoạt động của nhà truờng nhu một tổ chức giáo dục, bao gồm nhũng giá trị, nguyên tắc và truyền thống gắn kết mọi thành viên với nhau, được mọi nguời hiểu biết, tôn thờ, muốn sở hũu và chia sẻ, làm cho nhà truò̀ng trở nên khác biệt, tiêu biểu cho nhà truờng, tạo nên tính thuần khiết và toàn vẹn của nhà truờng. Toàn bộ những giá trị tạo nên văn hóa nhà trường thể hiện ở 4 lĩnh vực cơ bản, tạo nên cấu trúc của văn hóa nhà trường (Hình trên).

1. Văn hóa quản lí

2. Văn hóa giảng dạy

3. Văn hóa học tập

4. Văn hóa sinh hoạt tập thể và ứng xử xã hội trong trường
Trong mỗi lĩnh vực như vậy đều tồn tại 4 loại giá trị của văn hóa tổ chức. Trong văn hóa nhà trường thì văn hóa học tập là trung tâm. Nó không chỉ nói về học sinh, sinh viên mà nói chung về mọi thành viên nhà trường như một tổ chức học hỏi (Learning Organization) [5].

\section{3. Đặc điểm văn hóa úng xử ở trường đại học}

\subsubsection{VHUX ở trường đại học là VHUX của trí thức}

Tuyệt đại đa số thành viên trường đại học là trí thức: sinh viên, học viên cao học, nghiên cứu sinh, nhà giáo đại học, các chuyên gia khoa học, kĩ thuật, nghệ thuật, các nhà lãnh đạo, quản lí, cố vấn, hoạt động xã hội v.v... Trí thức luôn tiềm tàng và biểu hiện VHUX đặc trưng cho giới trí thức như tinh tế, đa dạng, ôn hòa, sâu sắc, giàu trí tuệ... và có thể nói có tính cầu kì, đôi khi thiếu bộc bạch, khó hiểu, nhiều sắc thái. 
1.3.2. VHUX ở trường đại học là VHUX của người trưởng thành

Toàn bộ thành viên của nhà trường đại học là những người trưởng thành, từ tuổi thanh niên cho đến tuổi già. Vì thế phong cách và kĩ năng hành vi ứng xử tuy có mẫu số chung là trí thức, nhưng mang đặc trưng của người lớn và có những khác biệt thế hệ. Lớp trẻ có VHUX sôi nổi, bộc trực hơn lớp trung và lớn tuổi. Khác biệt lứa tuổi đó tuy tồn tại nhưng những khác biệt cá nhân lại càng lớn. Cùng lứa tuổi nhưng VHUX của mỗi người vô cùng khác nhau. Chính vì thế các tổ chức và nhà trường mới phải đề ra và áp dụng các bộ qui tắc ứng xử để giúp những khác biệt cá nhân bớt xung đột nhau.

1.3.3. VHUX ở trường đại học là VHUXX đa lĩnh vực và giàu thông tin

Môi trường hoạt động và giao tiếp ở trường đại học chứa đựng nhiều quan hệ và lĩnh vực, trong đó thông tin phong phú và phức tạp. Mọi người phải thực hiện ứng xử trong các quan hệ quản lí, trong hoạt động và quan hệ chuyên môn (giảng dạy, nghiên cứu, tư vấn, đào tạo, bồi dưỡng, phát triển nghề nghiệp, học tập...), trong sinh hoạt, giải trí và hoạt động tập thể, trong quan hệ xã hội liên cá nhân và nhóm v.v... Cho nên VHUXX ở trường đại học luôn có tính chất phức tạp, đa phương, đa dạng.

1.3.4. VHUX ở trường đại học là một phần của VHUX nghề nghiệp

Khác với rất nhiều dạng tổ chức như bệnh viện, doanh nghiệp, cơ quan hành chính v.v..., VHUX ở trường đại học luôn có những nét sư phạm cho dù không phải là trường sư phạm. Đặc điểm này không chỉ thể hiện trong quan hệ giữa nhà giáo và sinh viên, học viên, mà kể cả trong các bộ máy quản lí, giảng dạy, nghiên cứu. Các thế hệ sau thường coi các thế hệ trước là bậc thầy, xưng hô và đối xử như với thầy cô mình. Các thế hệ trước thường có ý thức nêu gương, khoan hòa, nhiệt thành chia sẻ và nâng đỡ các thế hệ trước. Những quan hệ đó mang tính sư phạm, giàu tình cảm.

\section{Những vấn đề chủ yếu của văn hóa ứng xử học đường}

\subsection{Xung đột và quản lí xung đột}

Khái niệm xung đột chỉ hoàn cảnh hay trạng thái quan hệ trong đó diễn ra quá trình tuoong tác giũa hai bên (cá nhân, nhóm, phe phái) xoay quanh sụ việc hay vấn đề nảy sinh giũa ho mà không tuoong thích đồng thời với nhận thức, mong muốn, muc tiêu hay lợi ích của cả hai trong khi bên nào cũng muốn giải quyết vấn đề nhung vẫn muốn giũ lập truòng của mình, không muốn buông bỏ lợi ích của mình.

Chính tính chất của xung đột tự nó mở ra khả năng quản lí xung đột, chứ không chỉ thủ tiêu nó. Giải quyết xung đột là việc đơn giản hơn quản lí xung đột rất nhiều. Cách giải quyết xung đột đơn giản nhất là sa thải hay chuyển vị trí của một bên đương sự đi, hoặc sa thải cả hai, thế là xong. Nhưng quản lí xung đột thì có ý nghĩa hơn rất nhiều.

Quản lí xung đột (Conflict management) là quá trình hạn chế nhũng khía cạnh hay ảnh hương tiêu cực của xung đột đồng thời nâng cao nhũng khía cạnh hoặc ảnh hương tích cưc của xung đột để tăng cuờng sụ học hỏi và kêt quả làm việc của tổ chức, của nhóm, nâng cao tính hiệu quả hoạc thành tưu của tổ chức, chứ không nhằm giải quyết xung đột nhu là thủ tiêu nó. Giải quyết xung đột là thủ tiêu nó đi, khá đơn giản. Quản lí xung đột là thừa nhận nó, hạn chế hậu quả tiêu cực, lợi dụng mặt tích cực để tăng cường cơ hội học hỏi cũng như nâng cao động lực phát triển trong tập thể [4].

\subsection{Nguyên tắc quản lí xung đột}

\section{Suy nghĩ kĩ trước khi phản ứng}

Cần phải xem xét kĩ lưỡng và suy nghĩ mọi khía cạnh khi tiếp cận xung đột, nhất là ở học sinh, sinh viên. Không lấy lập trường chủ quan ép buộc để bên này thiệt thòi bên kia có lợi. Suy nghĩ về lí do, về tính chất nghiêm trọng đến đâu (đa số các xung đột ở trường đều không nghiêm trọng gì) chứ không vội vã quá cường điệu nó lên (ví dụ thành bạo lực học đường, thành vấn đề tư tưởng, đạo đức hay trật tự, an ninh xã hội). Cũng phải suy nghĩ về hậu quả xung đột và giải pháp quản lí của mình với mục tiêu tối thượng là vì lợi ích của trường và của cả hai bên đương sự.

\section{Lắng nghe chủ động và tích cực}

Lắng nghe chủ động và tích cực là phần quan trọng nhất trong giao tiếp, của hai bên đương sự cũng như giữa nhà quản lí và họ. Lắng nghe mới hiểu chuyện, căn nguyên và mức độ xung đột. Đa số xung đột là đơn giản, không quá phức tạp như ta tưởng, nếu biết lắng nghe sẽ vỡ lẽ ra. Chủ động nghe có nghĩa là nghe đúng chỗ, nghe những gì cần nghe. Đôi khi nhà quản lí nếu không cảnh giác sẽ nghe nhầm, hiểu nhầm vì đã nghe phải những điều không cần nghe, không xác thực hoặc vô nghĩa, nhất là tiếp xúc với đương sự mà chỉ nghe một tai. Tích cực có nghĩa là suy nghĩ khi nghe, làm chủ cuộc đối thoại và cân 
nhắc sau khi nghe chứ không thụ động nghe xui dại và ra quyết định thiếu sáng suốt về biện pháp quản lí xung đột cụ thể.

\section{Khuyến khích cách xử lí tốt đẹp}

Trong khi quản lí xung đột, nhà quản lí cần xử lí đẹp và khuyến khích hai bên đương sự xử lí đẹp với nhau. Bất kì hành vi hay thái độ đẹp nào của mỗi bên đều cần được nắm lấy tức khắc và phát huy nó lên bởi vì cho dù xung đột với nhau song cách xử lí đẹp không dẫn đến hành vi thô bạo hay bạo lực là điều nghiêm trọng và có tính chất hình sự. Xử lí đẹp cần tồn tại mãi ngay cả khi xung đột vẫn tiếp diễn bởi vì nó mang lại lợi ích cho trường và không có hại đến đương sự.

4. Tập trung vào vấn đề chứ không công kích con người

Xung đột phần nhiều luôn gắn liền với tình cảm, nhu cầu, chứ không hẳn do lí trí quyết định. Vì vậy mới nói nhiều xung đột thực ra không quá nghiêm trọng. Xung đột gắn với lí trí thì mới đáng lo ngại và quản lí khó khăn hơn, bởi vì nó thể hiện lập trường chín chắn sâu sắc của đương sự mà nhà quản lí muốn họ từ bỏ thì rất khó. Đa số xung đột nảy ra do thái độ, xúc cảm, tình cảm và hành vi "ngứa mắt" của hai bên khi tiếp xúc với nhau, vì thế phải xử lí tình cảm và tế nhị. Nhà quản lí cần nhớ rõ chúng ta xử lí vấn đề và hành vi, chứ không phải xét xử con người. Tuyệt đối không tấn công vào nhân cách người ta và cũng bằng mọi cách không cho phép hai bên đương sự tấn công vào nhân cách của nhau.

\section{Gánh nhận trách nhiệm đúng mực}

Nhà quản lí đương nhiên phải gánh trách nhiệm khi quản lí xung đột nếu hậu quả xử lí của mình có hại cho tổ chức hoặc cho đương sự. Song hai bên đương sự đều có phần trách nhiệm nhất định trong xung đột. Điều đó là sự thực khách quan mà nhà quản lí cần nhận thức rõ và làm cho hai bên hiểu rõ, tự giác về trách nhiệm của phần mình, không đổ lỗi hết cho bên kia. Với đương sự thì yêu cầu này là khó hơn nhà quản lí vì người trong cuộc thường khó nhận ra lỗi của mình. Hiểu điều này nhà quản lí mới tránh được nhầm lẫn hoặc xử lí thiên vị.

6. Sử dụng truyền thông trực tiếp

Có nghĩa rằng không dùng tin đồn, nghe mách lẻo hay qua miệng người khác mà xử lí và quản lí xung đột. Cũng có nghĩa nữa là chỉ nói điều gì ta muốn nói đến và chỉ rõ cái mà ta nói. Không nói chuyện vòng vo và không ám chỉ cái gì khác ngoài vấn đề trung tâm. Nguyên tắc này vừa thỏa mãn yêu cầu trung thực, thẳng thắn, tránh hiểu lầm, vừa giúp bảo mật câu chuyện và cũng tiết kiệm thời gian. Truyền thông trực tiếp chính là trực tiếp đối thoại song phương và đa phương. Khi đã bộc lộ quan điểm và giá trị công khai trước mặt nhau và rõ ràng ý tứ thì vấn đề không còn cơ hội để ẩn núp nữa, nó sẽ được giải quyết có thể bằng chính hành động hợp tác của các bên.

\section{Hướng vào tìm kiếm lợi ích}

Quản lí xung đột phải hướng đến lợi ích, trước hết của trường, của tập thể rồi sau là của hai bên đương sự. Dù xung đột có được giải tỏa hay không thì điều trọng yếu là lợi ích mà nhà quản lí phải tạo ra dựa trên những ảnh hưởng tích cực của xung đột. Xung đột có ý nghĩa nhất định trong việc tăng cơ hội học hỏi và rèn luyện kĩ năng sống trong tổ chức. Nó có thể góp phần làm cho môi trường nhà trường bớt tẻ nhạt và đa dạng hơn về phong cách. Rất nhiều xung đột xảy ra chỉ do phong cách ứng xử chứ không phải chuyện gì hệ trọng như đạo đức, pháp luật...

\section{Tập trung vào tương lai}

Để hiểu được xung đột, điều quan trọng là hiểu động lực của mối quan hệ bao gồm cả lịch sử quan hệ. Tuy vậy để quản lí xung đột tốt thì nhà quản lí phải hướng vào tương lai. Như thế tức là hết sức tránh nhùng nhằng đôi co về những chuyện dĩ vãng không bao giờ dứt. Khi đã bới nhau chuyện cũ thì cả hai bên đều coi như đã hết tỉnh táo và nhà quản lí xung đột cũng rơi vào mớ bòng bong. Khi đó nguồn gốc thực sự của xung đột sẽ nhạt đi và không có hướng xử lí sáng suốt cho cả đương sự lẫn nhà quản lí.

9. Lựa chọn sao cho cả hai bên và nhà trường cùng có lợi

Cần tìm cách đảm bảo với đương sự rằng ngày mai cả hai bên sẽ tốt hơn hôm nay vì xét đến cùng xung đột cũng là chuyện bình thường, nếu hòa giải tốt sẽ có những lợi ích nhất định cho hai bên. Nếu để xung đột phát triển theo hướng xấu đi thì đương sự chịu thiệt hại đầu tiên [6].

\subsection{Hòa khí và nâng cao hòa khí trong nhà}

\section{truò̀ng}

\subsubsection{Những nguyên tắc duy trì hòa khí}

1. Bắt đầu từ cán cân quyền lực hiện hành

Gìn giữ hòa khí đòi hỏi bắt đầu với những thứ như tất cả đang có, chứ không phải dựa dẫm vào cái gì đó trong quá khứ hay những hi vọng trong tương lai. Trong nhà trường, hiện trạng quyền lực thế nào thì phải bắt đầu từ đó. Không ít thủ trưởng mới nhậm chức thích làm xáo trộn quyền lực ngay khi nắm quyền tối cao. Điều này làm hại đến hòa khí trong 
trường. Ngay cả khi cần thay đổi thì phải áp dụng các nguyên tắc và chiến lược quản lí thay đổi, chứ không phải là thủ tiêu quyền lực của những nhân vật khác đồng sự với mình. Làm thế chắc chắn sẽ mất hòa khí, chẳng những khó thay đổi mà còn khó giữ ổn định cho trường. Nguyên tắc tôn trọng cán cân quyền lực để giữ gìn hòa khí xuất phát từ chỗ hiểu đúng bản chất của hòa khí. Nó là biểu hiện rõ nhất của sự công bằng về lợi ích, nhu cầu và khát vọng. Nếu xâm phạm vào những thứ này tức là làm lung lay cơ sở của hòa khí.

2. Bảo vệ cán cân quyền lực

Không chỉ bắt đầu chu kì quản lí, mà trước khi hoạch định tầm nhìn chiến lược mới, thì phải bảo vệ cán cân quyền lực đã hình thành, chứ không tìm cách phá vỡ nó hoặc làm sai lệch đi. Lời người xưa nói đến an hưởng thái bình là nghĩa như vậy. Phá vỡ cán cân quyền lực đang ổn thỏa tức là tự hại mình, là phát động tranh chấp và cuối cùng là "chiến tranh". Khi đó chỉ lo đối phó với "kẻ địch " cũng hết hơi sức thì còn đâu tâm trí để quản lí và lãnh đạo tổ chức. Thường thì tranh chấp sẽ không bao giờ dứt nếu chưa phân rõ thắng thua. Nếu vậy không bao giờ trong tổ chức giữ được hòa khí cần thiết. Cán cân quyền lực không có nghĩa thô thiển là phân quyền ở cùng cấp. Thủ trưởng phải là thủ trưởng, cấp phó là giúp việc, các cấp trung gian là những nhà quản lí điều hành tác nghiệp. Cán cân quyền lực xê dịch tức là ảnh hưởng đến toàn thể và gây ra những lỗi hệ thống khó sửa tại chỗ mà phải nhờ đến cấp trên can thiệp. Cấp trên đã can thiệp thì đương nhiên chẳng còn "cán cân" nào nữa mà sẽ xuất hiện ê kíp mới.

3. Cắt giảm mọi khoảng trống giữa kì vọng và quyền lực

Một là không đặt ra những kì vọng nằm ngoài tầm quyền lực của mình. Tại sao vậy? Nếu làm thế sẽ khiến tình hình rối mù lên thì hòa khí đâu còn nữa. Kì vọng như vậy khiến các chủ thể quyền lực khác lo ngại và sẽ nghĩ cách dò xét, chống đối, ít ra là ngấm ngầm. Đặt kì vọng vào chỗ rỗng không một mặt chả có ích gì, mặt khác gây nghi ngờ cho người khác. Hai là nên mạnh dạn cắt đứt khoảng cách giữa kì vọng và quyền lực nếu như cán cân quyền lực cho phép thực thi kì vọng đó. Nếu làm được thì tại sao lại không dám làm? Không làm tức là lãng phí quyền lực. Ba là cắt giảm khoảng trống bằng cách lấp đầy nó bằng nhiều thứ miễn là thích hợp, tức là bắc cầu cho kì vọng và quyền lực luôn gặp nhau. Đó là môi trường hợp tác và học hỏi. Đó là văn hóa nhà trường. Nghĩa là những kĩ năng và giá trị thúc đẩy quan hệ thân thiện, chia sẻ, sáng tạo, khoan dung...

\section{Chấp nhận một vài xung đột}

Hòa khí không có tính tuyệt đối. Nếu nó tuyệt đối thì chẳng có vấn đề gì nữa phải bàn và cuộc sống cũng chẳng còn thú vị. Nó có những kích thước khó đo lường cụ thể và có nhiều cấp độ. Những xung đột vô thưởng vô phạt tựa như những bất đồng, những khác biệt không thể dung nhau hoàn toàn có lí để tồn tại trong tổ chức và trong cuộc sống. Nhà quản lí cần chấp nhận chúng vì chúng có nhiều khía cạnh tích cực hơn tiêu cực xét từ lợi ích chung. Nói về độ bình yên tuyệt đối thì người ta chỉ có thể nghĩ đến hoang đảo hay nấm mồ, còn trên đời không bao giờ có. Vì vậy nhà quản lí không những không cần cố gắng thủ tiêu mọi xung đột mà phải quản lí chúng sao cho những xung đột ác tính phải tự chúng tiêu tan và những xung đột lành tính (một trong những biểu hiện của tính đa dạng văn hóa) vẫn tồn tại để mang lại nhiều cơ hội học hỏi cho tổ chức.

Các cấp độ của hòa khí cũng không dễ xác định, rõ ràng là có vấn đề như vậy nhưng không dễ phân tích. Nếu xếp thứ bậc từ cao xuống thấp của hòa khí trong tổ chức, thì có thể chấp nhận mô hình sau xét từ quan điểm quản lí xung đột.

- Hòa khí hồn nhiên không lẫn với sự nín nhịn hay e sợ giữa mọi người

Nhà trường có hòa khí ở đỉnh cao này thì chắc chắn là nơi có văn hóa nhà trường tốt, nhân sự có tính chuyên nghiệp cao, lãnh đạo có tín nhiệm lớn và hoạt động chuyên môn có hiệu quả cao, chất lượng nhân sự chuyên môn tốt. Hòa khí này không ngăn ai nói gì làm gì ngoài khuôn khổ pháp luật và chuẩn mực đạo đức, nhưng luôn tồn tại quan hệ đồng cảm và hòa ái. Ở cấp này vẫn có những xung đột lành tính và cần phải có thì tổ chức mới luôn có sinh khí và năng động.

- Hòa khí cần đến vai trò cầm trịch thường xuyên của lãnh đạo và qui chế, nội qui hay các thỏa thuận

Đây là cấp thấp hơn. Có nghĩa nếu buông tay là dễ mất hòa khí và xung đột sẽ xảy ra. Chúng ta chẳng chê gì hòa khí cấp này, bởi vì thế là rất tốt rồi. Vấn đề là nhà quản lí phải có cách buông dần sự can thiệp tùy theo khả năng "tự bơi” của hòa khí. Nó tiến triển tốt dần lên và bền vững thì sẽ trở thành hòa khí hồn nhiên. Cấp này có cả xung đột lành tính lẫn ác tính nhưng loại đầu chiếm ưu thế rõ rệt. 
- Hòa khí được giữ gìn vừa nhờ lãnh đạo vừa nhờ đến lòng khoan dung

Có nghĩa rằng hòa khí ở cấp này đầy bấp bênh và rủi ro. Giả định ai đó tự dưng không thiết khoan dung nữa là sẽ có chuyện. Lãnh đạo không quan tâm sát sao nữa là sẽ nảy sinh xung đột. Khoan dung hay độ lượng không phải là thứ không bao giờ mòn đi. Vì vậy bầu hòa khí kiểu này rất cần đến quản lí rủi ro và cần áp dụng các biện pháp cải thiện. Nó chứa những xung đột ác tính chiếm ưu thế so với những xung đột lành tính. Vấn đề là không nên nhắm mắt làm ngơ coi như không có chuyện gì.

- Hòa khí trong tình trạng khủng hoảng cục bộ

Nghĩa là chỉ có hòa khí chút nào đó trong các đơn vị bộ phận, trong các nhóm nhất định do cố kết về lợi ích chung nên tồn tại (chung thuyền chung lái). Xét tổng thể, không có hòa khí trong toàn trường hoặc có nhưng rất bấp bênh và mong manh. Thậm chí có cả những xung đột nhóm có tính tập thể. Đây là tình trạng hòa khí ở cấp báo động. Cần phải áp dụng các nguyên tắc và chiến lược quản lí khủng hoảng để hạn chế dần các tác động tiêu cực, cải thiện các quan hệ và môi trường văn hóa, chuyên môn.

- Hòa khí ở tình trạng khủng hoảng toàn diện

Nghĩa là không có hòa khí trên thực tế. Nếu như tổ chức vẫn làm việc thì đó là do chưa có quyết định giải thể. Có thể trong tâm trí và mong đợi ở nhiều người, vẫn tồn tại hòa khí. Song bối cảnh chung là những biểu hiện mất phương hướng về quan hệ, mất tin tưởng hoặc thái độ thơ ơ với công vụ. Nền tảng của hòa khí cấp này chính là những xung đột ác tính (có tính chất hủy hoại) đang có dịp hoành hành.

\section{Hạn chế tối đa khả năng thành công của bạo lực}

Bạo lực thành công luôn khuyến khích hoặc đẻ ra bạo lực mới. Ở ngay chủ thể hoặc lây sang người khác. Bạo lực thành công cũng gây nên nỗi oán hận sâu xa cho nạn nhân. Bạo lực thành công cũng gây nghiện như ma túy, hễ xài được một lần là lần sau sẽ nghĩ ngay đến. Vì vậy nhà quản lí cần tìm cách hạn chế tối đa khả năng thành công của bạo lực, tốt nhất là ngăn chặn tuyệt đối không cho nó xảy ra. Nhưng phạm vi đáng lo nhất là học sinh, sinh viên, chứ không phải các thầy cô giáo. Mặc dù bạo lực ở học sinh chưa phải là bạo lực thực sự, mà chỉ là hành vi có màu sắc bạo lực, song nếu không bị ngăn chặn đúng lúc nó sẽ tiến triển đúng nghĩa bạo lực.
2.3.2. Những nguyên tắc nâng cao hòa khí

\section{Xem xung đột là chuyện bình thường}

Chuyện thường có vài nghĩa. Nó là phổ biến, thường thường, đâu đâu và bao giờ cũng có. Nó không phải chuyện gì nghiêm trọng, vì nó vốn sinh ra cùng với đời sống con người, làm nên ý vị của cuộc sống. Cuộc đấu tranh sinh tồn trong giới động vật thì không gọi là xung đột vì xung đột là khái niệm gắn với xã hội có ý thức. Xung đột không có khuynh hướng tiêu diệt nhau, một mất một còn. Nó là một hình thức giao tiếp bình thường. Nó còn bình thường ở chỗ không bao giờ biến mất tuyệt đối ở con người, không có xung đột trong đời sống mới là chuyện lạ. Xung đột còn là chuyện bình thường nếu ta xét từ nguồn gốc của nó theo nguyên tắc phân tâm luận. Ở chính mỗi con người đã có sẵn mầm mống của xung đột - đó là xung đột thường xuyên giữa cái Tôi với cái Nó và cái Siêu Tôi. Ba thứ này vốn ở mỗi người thì sao trong xã hội lại không có xung đột! Nó là chuyện thường nên trong đời sống xã hội con người phải có pháp chế, pháp luật và thiết chế đạo đức, văn hóa, khoa học để quản lí xung đột. Khi đã quản lí tức là thừa nhận sự tồn tại của nó là bình thường. Nếu sự gì kì quái, bất thường xuất hiện thì phải tiêu diệt nó chứ không phải quản lí.

Xem xung đột là chuyện thường chính là bước đầu tiên để tránh và ngăn chặn bạo lực. Giả định rằng chúng ta có cách làm tẹt mọi xung đột, không cho chúng phát tiết ra. Vậy cái gì sẽ tiếp theo? Không phải hòa khí, hòa bình mà chính là bạo lực và chiến tranh, hình thức khủng khiếp nhất của xung đột chứ không phải cái gì khác. Như vậy chúng ta chọn xung đột là thứ tốt hơn và tự nhiên hơn chứ không chọn bạo lực và chiến tranh. Từ bản chất, bạo lực và chiến tranh còn gài trong đó những thứ ngụy giá trị, phản giá trị rất hiểm hóc. Còn xung đột vẫn có "vẻ đẹp" của nó.

2. Xử lí các vấn đề thường nhật theo những qui tắc quyết định đẹp

Theo nghĩa dân gian, quyết định đẹp có nghĩa làm hài lòng mọi người. Nhưng trong khoa học quản lí, ngoài nghĩa đó ra thì đẹp còn là công bằng, công khai, sòng phẳng, đúng đạo lí mà lại tình cảm nữa. Nếu làm được như vậy mà vẫn còn ai đó hậm hực thì người đó cũng không đáng để tâm và người như thế cũng không kiếm đâu ra kẻ muốn xung đột với mình. Chúng ta biết rõ cạnh tranh hay hợp tác cũng vậy. Chẳng ai thèm cạnh tranh với kẻ hết hơi không có sức cạnh tranh. Cũng không ai muốn hợp tác với 
người không ngang ngửa với mình mà đang ở "chiếu dưới”.

Bản chất con người vốn không đến nỗi tham lam ở mức độ không muốn cho ai hưởng cái gì mà mình hưởng hết. Chính vì thiếu công bằng, thiếu quyết định đẹp nên mới cổ vũ tính tham lam nảy nở mạnh. Tự thân những quyết định đẹp theo những qui tắc nghiêm minh đã là những ràng buộc vô cùng hiệu lực và khuyến khích các hành vi đẹp, thái độ đẹp của mọi người trong làm việc và giao tiếp. Nếu có xung đột thì đó chỉ là những xung đột vô hại, hơn nữa còn có ích cho tập thể. Chúng còn là những "chuyện vui vẻ" tự nhiên làm cho đời sống tập thể ấm áp hơn. Những điều kiện này là cần và đủ để nâng cao hòa khí trong tổ chức. Tiếc rằng việc thực hiện các quyết định đẹp trong thực tế không phải là dễ vì có nhiều yếu tố khách quan chi phối.

\section{Thể chế hóa những thủ tục điều chỉnh}

Tất cả những gì sẽ cần có lúc điều chỉnh trong nhà trường như nhân sự, cơ cấu, bộ máy, hoạt động chuyên môn, kế hoạch, chế độ tài chính nội bộ, chính sách xã hội nội bộ v.v...đều cần được thể chế hóa về thủ tục. Khi điều chỉnh chúng mới có căn cứ nhất quán mà ra quyết định. Nếu không làm như vậy, tùy tiện điều chỉnh thì sẽ bị xem là độc đoán, chủ quan, hoặc có tư lợi nào đó trong quyết định, nhất là khi điều chỉnh nhân sự, cho dù quyết định đó không sai. Thể chế hóa có nhiều ý nghĩa và tác dụng cụ thể:

- Củng cố nền nếp hành chính chung của trường, tạo ra tập quán làm việc nghiêm túc và chuyên nghiệp.

- Tạo cơ hội nâng cao nhận thức của mọi người về lợi ích chung và lợi ích riêng tư cũng như định hướng thái độ của họ trong quan hệ công vụ.

- Tạo căn cứ và điều kiện có tính ổn định cho chính nhà quản lí mỗi khi cần ra quyết định điều chỉnh, bớt phải họp hành vì sẵn có thủ tục, qui trình.

- Thể hiện rõ ràng tính công khai, minh bạch và dân chủ trong quản lí bằng các công cụ thể chế hóa chứ không phải bằng cách nói suông.

- Giảm bớt những công việc sự vụ lặt vặt phiền hà trong quản lí mỗi khi cần thay đổi hay điều chỉnh, đặc biệt về khía cạnh nhân sự.

- Nâng cao khả năng ủy quyền bởi vì thủ tục và qui trình cho phép thủ trưởng có thể ủy quyền cho cấp phó hoặc các nhà quản lí trung gian kí thay trong những trường hợp cần thiết mà không phải lo ngại.

\section{Vượt qua các sức ép}

Thế chế hóa còn được áp dụng cho chính xung đột, qua đó thừa nhận nó là một đối tượng quản lí trong nhà trường. Việc này sẽ có hiệu quả cao khi các lợi ích là đa dạng và các vấn đề không phải có tính chất sống còn. Xung đột phần nào tạo ra sức ép đối với nhà quản lí, thường là làm cho họ lúng túng, mất tập trung vào nhiệm vụ chủ yếu là lãnh đạo và quản lí trường. Vì vậy thể chế hóa xung đột là cách giảm nhẹ sức ép. Xử lí các xung đột nào đó không quá nghiêm trọng thì không riêng thủ trưởng mà các cấp quản lí trực tiếp của đương sự cũng căn cứ vào thể chế nội bộ đó mà tiến hành, không ngại mình làm sai và cấp trên cũng yên tâm khi cấp dưới làm. Khi xung đột được thể chế hóa, tự nhiên nó giảm bớt ảnh hưởng tự phát. Đa số những ảnh hưởng của nó đã được kiểm soát, và được hướng vào phát huy mặt tích cực đối với nhà trường.

\section{Nâng cao và đảm bảo tự do}

Tự do cá nhân và tự do nhóm không chỉ cần được tôn trọng mà còn phải được bảo vệ và nâng cao. Đây là nền móng sâu xa nhất để nâng cao hòa khí trong nhà trường. Bản chất tự nhiên của hòa khí, hòa bình chính là tự do. Tự do trước hết gắn với cá nhân và nhóm, không có tự do chung chung. Trong quan niệm tự do nhóm, cần hiểu rằng nhóm là khái niệm rộng, có thể là nhóm nhỏ, tổ chức, cộng đồng địa phương, cộng đồng quốc gia, cộng đồng quốc tế. Bản chất của tự do cũng chính là hòa khí, hòa bình. Đi đâu, nghĩ gì, làm gì cũng vướng phải xung đột nguy hiểm, cũng gặp tai họa thì sẽ không có tự do, không thể tự do. Trong tổ chức cụ thể như nhà trường, có những nhóm nhỏ hơn và các cá nhân thành viên, tự do và hòa khí trong đó cũng gắn với nhau. Nâng cao và đảm bảo tự do trên nguyên tắc tuân thủ pháp luật và các ràng buộc đạo đức, văn hóa chung cũng là hình thức hiệu quả để phát triển nghề nghiệp của nhà giáo, phát triển người học.

\section{Kết luận}

VHUXX là vấn đề của khoa học quản lí, khoa học giáo dục và xã hội học. Khi đặt ra và giải quyết vấn đề này như một lĩnh vực của văn hóa nhà trường với vai trò cụ thể của mỗi thành viên thì khía cạnh giáo dục, quản lí và xã hội cần được coi trọng. Trong lĩnh vực này cần phải triệt để áp dụng phong cách tham gia khi quản lí. 


\section{REFERENCES}

[1] Deal T. E. and Kennedy, A. A. (1982, 2000), Corporate Cultures: The Rites and Rituals of Corporate Life, Harmondsworth, Penguin Books, 1982; reissue Perseus Books 2000.

[2] Deal, T.E., \& Peterson, K.D. (1994). The leadership paradox: Balancing logic and artistry in schools. San Francisco: Jossey-Bass.

[3] Deal, Terrence E. (1993), "The Culture of Schools." In Educational Leadership and School Culture edited by Marshall Sashkin and Herbert J. Walberg. Berkeley, California: McCutchan Publishing.

[4] Đặng Thành Hung (2014), Tiếp cận quản li giáo dục hiện đại, Tập 1 và Tập 2, Đại học su phạm Hà Nội 2.

[5] Đặng Thành Hưng (2016), "Văn hóa tổ chức và văn hóa nhà trường trong quản lí giáo dục", Tạp chí khoa học giáo dục, số 124 tháng 1/2016, tr. 10-12,15.

[6] Đặng Thành Hưng (2016), "Đặc điểm và nguyên tắc quản lí xung đột trong giáo dục", Tạp chí Quản lí giáo duc, Vol.8, No 10, pp. 8-11.

[7] J. Smyth, P. McInerney, R. Hattarn, M. Lawson (1999), School Culture As the Key to School Reorm, Flinders Institute for Study of Teaching, Flinders University of South Australia.
[8] Kotter, J. P.; Heskett, James L. (1992), Corporate Culture and Performance. New York: The Free Press. ISBN 0-02-918467-3.

[9] Needle, David (2004). Business in Context: An Introduction to Business and Its Environment. ISBN 978-1861529923.

[10] Phillips, G. (1993). The school-classroom culture assessment. Vancouver, British Columbia: Eduserv, British Columbia School Trustees Publishing.

[11] Ravasi, D.; Schultz, M. (2006). "Responding to organizational identity threats: Exploring the role of organizational culture". Academy of Management Journal 49 (3): 433-458.

[12] Schein, Edgar (1992), Organizational Culture and Leadership: A Dynamic View. San Francisco, CA: Jossey-Bass.

[13] Stolp, Stephen, and Stuart C. Smith (2994), "School Culture and Climate: the Role of the Leader". OSSC Bulletin. Eugene: Oregon School Study Council, January 1994

[14] Wagner, C. (2000). School culture analysis. Address presented at the annual meeting of the Manitoba Association of Resource Teacher (MART). Winnipeg, Manitoba.

\section{CONFLICTING MANAGEMENT, IMPROVING PEACE AND DEVELOPING UNIVERSITY CULTURE}

\section{Article info}

Recieved:

03/8/2020

Accepted:

20/9/2020

Keywords: cultural behavior, school culture, conflict management, development of university culture

\begin{abstract}
University behavioral culture is a part of the university culture. It is concerned with conflict management, easing and enhancing the harmony within the organization so it is imperative to approach these problems in a participatory style. This article helps to explain some of these problems.
\end{abstract}

